\title{
Tropical Atlantic air-sea interaction and its influence on the NAO
}

\author{
Yuko Okumura and Shang-Ping Xie \\ Department of Meteorology, University of Hawaii \\ Atusi Numaguti and Youichi Tanimoto \\ Graduate School of Environmental Earth Science, Hokkaido University, Sapporo, Japan
}

\begin{abstract}
An atmospheric general circulation model (AGCM) is forced with a prescribed SST dipole anomaly in the tropical Atlantic to investigate the cause of crossequatorial SST gradient (CESG) variability and its teleconnection to the extratropics. The model response bears a striking resemblance to observations in both the tropics and extratropics. The tropical response is robust and can act to reinforce the prescribed SST anomalies through windinduced evaporation. A new feedback mechanism involving low-level stratiform clouds in the subtropics is also identified in the model and observations. The tropical SST dipole forces a barotropic teleconnection into the extratropics that projects onto the North Atlantic Oscillation (NAO). It further induces the extratropical portion of the North Atlantic SST tripole when the AGCM is coupled with an ocean mixed layer model. CESG variability thus appears to be the centerpiece of a pan-Atlantic climate pattern observed to extend from the South Atlantic to Greenland.
\end{abstract}

\section{Introduction}

Unlike the Pacific, the tropical Atlantic does not have a dominant mode of variability, but has several modes which appear to coexist. The search for such modes is a subject of current active research. Among them is a SST dipole pattern that is most pronounced on decadal time scales, and is known for its influence on the Atlantic Intertropical Convergence Zone (ITCZ) [Servain, 1991; Nobre and Shukla, 1996] and on rainfall over the Sahel [Folland et al., 1986] and northeast Brazil [Carton et al., 1996; Mehta, 1998]. Our understanding of this tropical Atlantic dipole is inadequate at this time, and it is currently under debate whether it represents a mode of air-sea interaction [Chang et al., 1997; Xie and Tanimoto, 1998] or is just a fortuitous coincidence between independent SST variability on both sides of the equator [Houghton and Tourre, 1992; Dommenget and Latif, 2000]. Because of the limited length of data records, it is difficult to unambiguously determine physical modes in the tropical Atlantic from observations alone. Ocean models forced by observed winds succeed in reproducing cross-equatorial SST gradient (CESG) variability [Carton et al., 1996; Xie and Tanimoto, 1998]. By contrast, simulations with observed SSTs as forcing disagree strongly among AGCMs where trade wind anomalies, which are observed

Copyright 2001 by the American Geophysical Union.

Paper number 2000GL012565. 0094-8276/01/2000GL012565\$05.00 and required for positive feedback onto the ocean, are confined to a narrow equatorial region [Chang et al., 2000] or do not exist at all [Dommenget and Latif, 2000; Sutton et al., 2000].

There is some observational evidence for a linkage between the CESG and extratropical variability like the NAO [Xie and Tanimoto, 1998; Rajagopalan et al., 1998], but models do not agree on this, either [Chang et al., 2000; Sutton et al., 2000; Dommenget and Latif, 2000; Robertson et al., 2000; Watanabe and Kimoto, 1999]. This disagreement may be partially due to the difficulty in detecting climate signals in the noisy extratropics. Here we carry out a set of long AGCM integrations designed to yield stable statistics, and investigate the cause of CESG variability and its teleconnection to the extratropics.

\section{GCM experiments}

The global AGCM is a Japanese community model described by Numaguti [1999]. We use a T21 version with 20 sigma levels in the vertical. Previous studies indicate that extratropical response to ENSO-related tropical SST anomalies (SSTAs) is captured quite well by low-resolution AGCMs, albeit with slightly reduced amplitudes in comparison with high-resolution models [Lau and Nath, 2001].

We carry out three simulations. In the control, monthly climatological SSTs are prescribed. Then, a dipole pattern of SSTAs is placed in the tropical Atlantic, with climatological SST prescribed elsewhere. The SSTAs are zonally uniform and anti-symmetric about the equator with extrema of $\pm 1.0 \mathrm{~K}$ at $15 \mathrm{~N} / \mathrm{S}$. A pair of positive and negative dipole runs are made, with the positive SST pole in the northern and southern tropics, respectively. A perfect dipole pattern of SSTAs is not often observed in the tropical Atlantic [Houghton and Tourre, 1992; Mehta, 1998], presumably because of the interference by other modes of comparable amplitudes. We choose this dipole pattern because it maximizes the CESG to which the Atlantic ITCZ is sensitive. Here we do not presume that the dipole is an intrinsic mode of SST variability, but instead ask whether the atmospheric response can help maintain such a SST configuration if it ever appears. We keep SSTAs constant in time and integrate the model for 80 years in each of the experiments. This long duration of integrations ensures stable statistics, thereby circumventing the problem of differentiating climate signals from atmospheric internal variability that faces ensemble simulations with global, time-variant SSTs. 

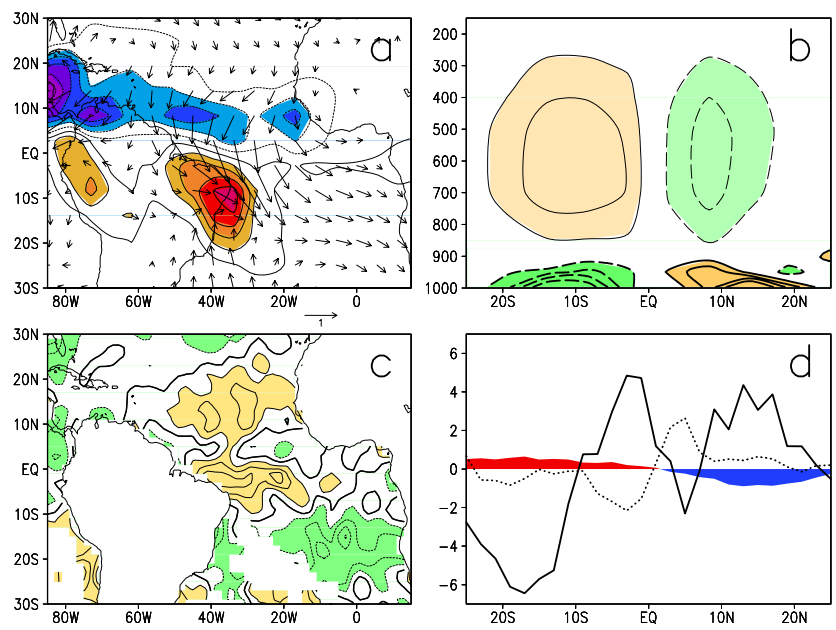

Figure 1. a, Annual-mean wind velocity $\left(\mathrm{m} \mathrm{s}^{-1}\right)$ at $950 \mathrm{hPa}$ and precipitation anomalies in response to a negative SST dipole in the tropics. Contour intervals are $200 \mathrm{~mm} \mathrm{yr}^{-1}(-300,-100$, $100 \ldots)$. b, Annual-mean cloud water anomalies zonally averaged between $0-50 \mathrm{~W}$ in the model. Contour intervals for cloud water in cumulus convection (thin lines) and large-scale condensation (thick) are $5.0 \times 10^{-7}$ and $5.0 \times 10^{-6} \mathrm{~kg} \mathrm{~kg}^{-1}$, respectively. The zero contours are omitted. c, Observed Feb.- Apr. cloud cover anomalies (contour intervals: $3.0 \%$ ), defined as the difference between six negative phase years $(1972,73,74,84,85 \& 86)$ and six positive phase years $(1968,69,70,79,80 \& 81)$, following Xie and Tanimoto, [1998]. d, Same as $\mathbf{c}$ but for zonal-mean anomalies of SST (K; shaded) and cloud cover (\%; solid line) along with surface wind divergence $\left(10^{-6} \mathrm{~s}^{-1}\right.$; dotted).

\section{Tropical feedback}

The GCM's response is very robust in the tropics, where time averaging for a few years is sufficient to obtain stable statistics. The ITCZ is anomalously displaced toward the anomalously warm hemisphere (Fig. 1a). The wind response is characterized by weakened (enhanced) trade winds over the positive (negative) lobe of the SST dipole, in support of the wind-evaporation-SST (WES) feedback [Chang et al., 1997; Xie and Tanimoto, 1998]. A southward SST gradient induces cross-equatorial northerly winds. The Coriolis force acting upon these northerlies induces an anomalous westerly (easterly) component south (north) of the equator. These westerly (easterly) winds, superimposed on the mean easterly trades, reduce (enhance) sea surface evaporation in the southern (northern) tropics, thereby reinforcing the initial SST dipole. Being a measure of this ocean-atmospheric feedback, the wind-induced latent heat flux anomalies are similar to wind velocity ones in pattern and on the order of $20 \mathrm{~W} / \mathrm{m}^{2}$ in magnitude. The passive Newtonian cooling due to the SST depedence of evaporation is twice as large in the model, keeping the coupled system from becoming unstable. Nevertheless, the WES feedback reduces the damping rate of the resultant coupled mode, which can then be preferentially excited by stochastic forcing [Xie and Tanimoto, 1998].

Because the Atlantic climatology is highly asymmetric about the equator, the response shows slight differences between the positive and negative dipole runs. Atmospheric response tends to be stronger to a negative SST dipole that allows the ITCZ to move to the south of the equator during boreal spring.

Our analysis of observations reveals an additional positive feedback of subtropical low-level clouds on the SST dipole. Fig. 1c shows the cloud cover difference between negative and positive phases of CESG variability, based on the comprehensive ocean-atmosphere data set (COADS). The near-equatorial (10S-10N) changes in cloudiness are associated with the meridional shift of deep convective clouds in the ITCZ (Fig. 1d), giving rise to a negative feedback onto local SSTAs. The broader cloudiness anomalies in the subtropics, by contrast, are not related to surface wind convergence, but instead appear to be associated with low-level stratiform clouds. Sea surface cooling (warming) increases (decreases) the static stability at the top of the planetary
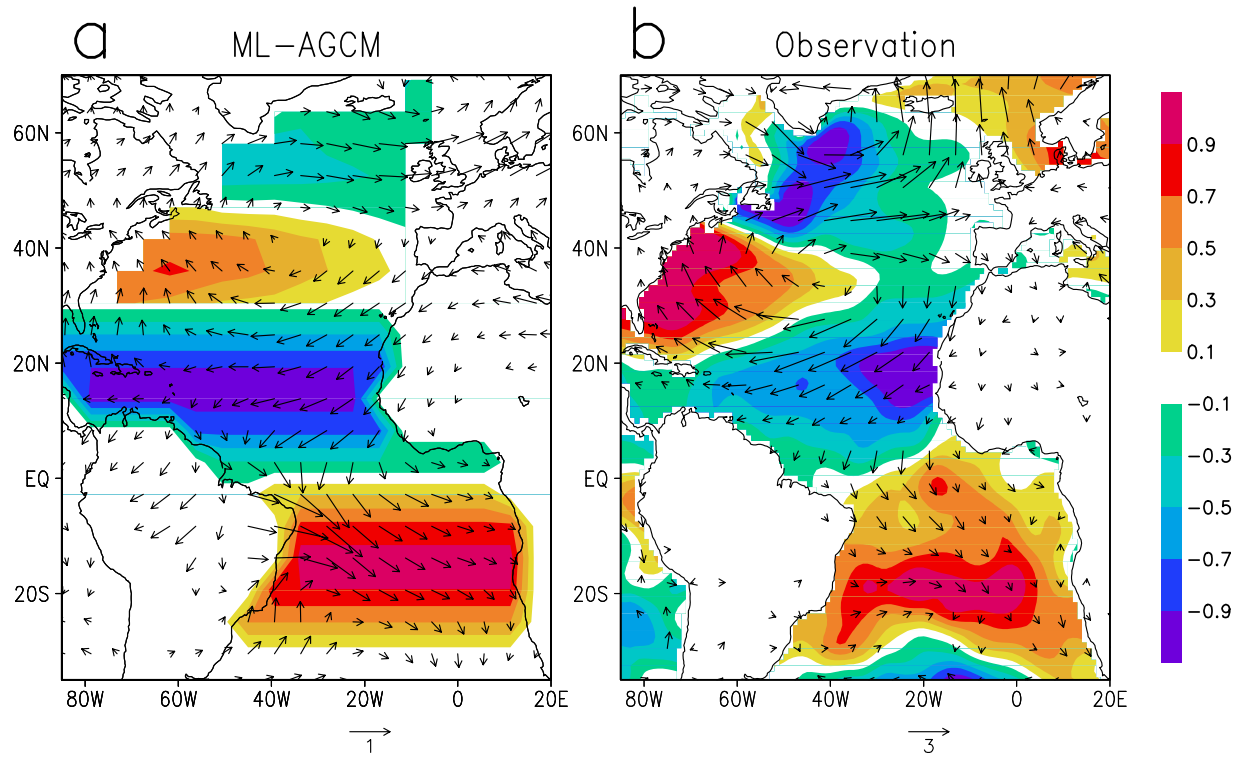

Figure 2. a, Jan.-Mar. anomalies of wind velocity $\left(\mathrm{m} \mathrm{s}^{-1}\right)$ at $950 \mathrm{hPa}$ and SST $(\mathrm{K})$ in ML-AGCM run. These wind anomalies are similar to those in the stand-alone AGCM. SST anomalies within 30N/S are prescribed. b, Same as a, but for observed SST (COADS) and surface wind velocity (NCEP reanalysis) with the same compositing method as in Fig. 1c. 
boundary layer (PBL) and hence the amount of stratus [Klein and Hartmann, 1993]. These clouds reflect solar radiation back to space, and the cloud-induced changes in surface solar radiation amplify the initial SST changes [Philander et al., 1996]. The model captures this cloud anomaly pattern, with deep and shallow clouds responding in opposite ways to local SSTAs (Fig. 1b). Compared to observations, anomalous deep-clouds spread too broadly in the meridional direction, an artifact of the low model resolution. The associated solar radiation anomalies are about half of the wind-induced latent heat flux near the centers of the SST dipole. The longwave radiation anomalies are much smaller and not well organized in space.

To investigate whether the interhemispheric response of the atmosphere seen in Fig. 1 is an artifact of imposing dipole SSTAs, we have repeated the experiments by prescribing only the northern or southern lobe of the dipole. The model response is strong and similar to that of the previous experiments over the half of the tropics where SSTAs are imposed. Wind anomalies of opposite sign are found in the other hemisphere, allowing an interhemispheric interaction. While the low-level cloud response is largely local, cloud cover anomalies of reduced magnitude $-10-20 \%$ compared to the dipole runs - remain in the hemisphere free of SSTAs due to adjustment in the local Hadley circulation. Thus, the atmospheric response is interhemispheric
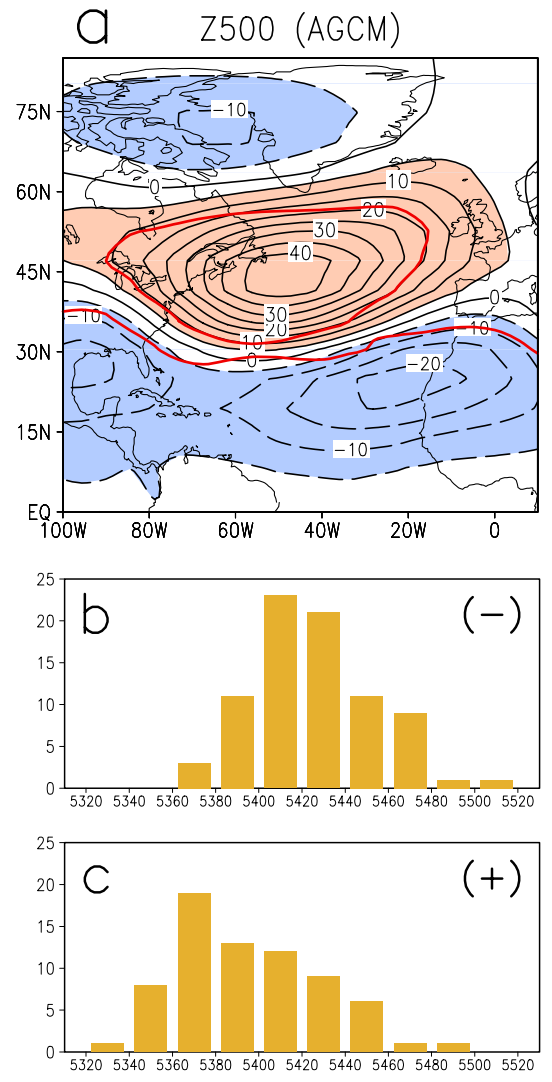

Figure 3. a, Jan.-Apr. difference in $500 \mathrm{hPa}$ geopotential height (m) between the negative and positive dipole runs of the AGCM. Within the red contours, the difference exceeds the $99 \%$ confidence level based on a 2-tailed t-test. Histograms of $500 \mathrm{hPa}$ geopotential height in the Azores (70-20W, 35-55N) for $\mathbf{b}$, the negative and $\mathbf{c}$, positive dipole runs. The negative (positive) dipole run lasts for 80 (70) years. even if SSTAs are confined to one side of the equator. In some coupled models, such interhemispheric interaction that yields positive ocean-atmospheric feedback is instrumental in forming a dipole SST pattern in the first place [Chang et al., 1997; Xie and Tanimoto, 1998]. When this AGCM is coupled to an ocean model with the thermocline feedback suppressed, a dipole oscillation indeed appears due to the WES and stratus-SST feedback [Xie and Saito, 2001].

\section{Tropical-extratropical connection}

Despite the time-invariant SSTAs, the model response displays distinct seasonality due to the seasonal cycle in solar radiation and climatological SST. In the tropical North Atlantic, the WES-favoring anomalous winds become stronger in boreal winter and occupy the whole SSTA lobe (compare Figs. 1a and 2a) as in observations (Fig. 2b). The seasonality in the South Atlantic is much weaker as expected. The anomalous trade winds poleward of the SSTA extrema cannot be explained by linear baroclinic models [Lindzen and Nigam, 1987], which predict opposite wind anomalies because in these models, a negative (positive) sea level pressure (SLP) anomaly forms over a warm (cold) SSTA. These subtropical wind anomalies are instead part of an equivalent barotropic response to the SST dipole and the anomalous displacement of the ITCZ. As can be inferred from Fig. 2a, geopotential height anomalies positive at $950 \mathrm{hPa}$ between the equator and $50 \mathrm{~N}$, in (out of) phase with the $500 \mathrm{hPa}$ anomaly center in the mid-latitude (tropical) North Atlantic (Fig. 3a). These barotropic anomalies are strongest in boreal winter when the enhanced westerly jet allows barotropic waves to be stationary.

The extratropical response induced by the tropical SST dipole has a projection onto the well-known NAO pattern from boreal winter to early spring in both the positive and negative dipole runs (Fig. 3). Similar results suggesting this tropical forcing of NAO have been previously reported [Robertson et al., 2000; Watanabe and Kimoto, 1999], but they are based on a single AGCM integration. Large internal variability renders the detection of climate signals in the extratropical atmosphere a challenge for GCM modeling. Long integrations with time-invariant SST forcing here allows a straightforward determination of the statistical significance of model response. A visual examination of histograms of geopotential height over the Azores indicates a systematic shift between the positive and negative dipole runs, with the shape of the probability distribution largely unchanged (Figs. 3bc). A t-test puts this change over the Azores above the 99\% significance level. Because the year-to-year variability here is purely due to atmospheric chaos, we assume $\left(N_{n}+N_{p}-2\right)$ degrees of freedom, with $N_{n}=80\left(N_{p}=70\right)$ being the number of years for which the integrations are made for the negative (positive) dipole. In the Icelandic low where atmospheric internal variance is higher, the response is much less significant with a confidence level of $75 \%$. Significant changes are also found in the Atlantic storm track (not shown). The dynamic mechanisms for this teleconnection need further investigation, but the meridional shift of the ITCZ and the associated adjustment in the winter-hemisphere Hadley circulation appear to be key elements.

The extratropical model response compares favorably with observations, and has a strong signature in the surface 
wind, which may induce additional SSTAs. We conduct an additional set of simulations where a motionless 50m-deep ocean mixed layer (ML) model is placed in the extratropical North Atlantic poleward of $30 \mathrm{~N}$. This appears to be a reasonable first approximation since surface heat flux is the major mechanism for extratropical SST variability [Alexander, 1992]. SSTAs computed from this ML model are allowed to feedback onto the atmosphere. In the tropical Atlantic, the same time-invariant SST dipole is imposed, and SSTs outside the Atlantic follow monthly climatology. This MLAGCM is integrated for 80 years for each of the positive and negative dipole cases.

Fig. 2 shows January-March SST and wind anomalies when there is a negative SST dipole in the tropics. A strong resemblance is apparent between the model and observed SST patterns in the extratropical North Atlantic, with centers of action off the United States and off Canada. These SSTAs are associated with the changes in the speed of the prevailing winds. In particular, the positive SSTA center off the eastern United States is caused by the weakened cold surge. These extratropical SSTAs appear to weakly reinforce the atmospheric anomalies induced by the tropical SST dipole. In the ML-AGCM runs, the $500 \mathrm{hPa}$ height anomalies over the Icelandic low become stronger from $10 \mathrm{~m}$ to $15 \mathrm{~m}$ and their t-test significance level increases from $75 \%$ to above $99 \%$. Interactive SSTs in the model extratropics apparently lead to a stronger atmospheric response as suggested by ML-AGCM experiments [Lau and Nath, 2001] and a simple coupled model [Bretherton and Battisti, 2000], helping the tropical-forced teleconnection extend farther northward and reach the Icelandic pole of the seesawing NAO [Rodwell et al., 1999].

\section{Summary}

It is difficult to determine conclusively from observations alone whether the observed wind and cloud patterns in Figs. $2 \mathrm{~b}$ and $1 \mathrm{c}$ form in response to the SST dipole, or they serve only as a one-way forcing to the ocean without knowing the oceanic conditions. Our model simulation provides strong evidence, judged by its close resemblance to observations and by the sign of atmospheric feedback, that these atmospheric anomalies are indeed a response, one that helps sustain SSTAs with an interhemispheric dipole pattern. This response is not confined to the tropics, but induces highly significant changes in the Azores high and to a lesser degree, in the Icelandic low. Such an interaction between the tropical and extratropical North Atlantic may be a two-way process, where extratropical variability can induce tropical changes via the Azores variability [Xie and Tanimoto, 1998].

Acknowledgments. We thank N.-C. Lau and S. KemballCook for helpful comments. IPRC contribution \#73 and SOEST contribution \#5328.

\section{References}

Alexander, M. A., Midlatitude atmosphere-ocean interaction during El Niño. Part I: The North Pacific Ocean, J. Climate, 5, 944-958, 1992.

Bretherton, C. S. and D. S. Battisti, An interpretation of the results from atmospheric general circulation models forced by the time history of the observed sea surface temperature distribution, Geophys. Res. Lett., 27, 767-770, 2000.
Carton, J. A., X. Cao, B. S. Giese and A. M. da Silva, Decadal and interannual SST variability in the tropical Atlantic Ocean, J. Phys. Oceanogr., 26, 1165-1175, 1996.

Chang, P., L. Ji and H. Li, A decadal climate variation in the tropical Atlantic ocean from thermodynamic air-sea interactions, Nature, 385, 516-518, 1997.

Chang, P., R. Saravanan, L. Ji and G. C. Hegerl, The effects of local sea surface temperatures on atmospheric circulation over the tropical Atlantic sector, J. Climate, 13, 2195-2216, 2000.

Dommenget, D. and M. Latif, Interannual to decadal variability in the tropical Atlantic, J. Climate, 13, 777-792, 2000.

Folland, C., T. Palmer and T. Parker, Sahel rainfall and worldwide sea surfaced temperatures: 1901-85, Nature, 320, 602606, 1986.

Houghton, R. W. and Y. M. Tourre, Characteristics of lowfrequency sea surface temperature fluctuations in the tropical Atlantic, J. Climate, 5, 765-771, 1992.

Klein, S. A. and D. L. Hartmann, The seasonal cycle of low stratiform clouds, J. Climate, 6, 1587-1606, 1993.

Lau, N. -C. and M. J. Nath, Impact of ENSO on SST variability in the North Pacific and North Atlantic: Seasonal dependence and role of Extratropical air-sea coupling J. Climate, submitted, 2001.

Lindzen, R. S. and S. Nigam, On the role of sea surface temperature gradients in forcing low level winds and convergence in the tropics, J. Atmos. Sci., 44, 2418-2436, 1987.

Mehta, V. M., Variability of the tropical ocean surface temperature at decadal-multidecadal time scales. Part I: The Atlantic Ocean, J. Climate, 11, 2351-2375, 1998.

Nobre, P. and J. Shukla, Variations of sea surface temperature, wind stress and rainfall over the tropical Atlantic and South America, J. Climate, 9, 2464-2479, 1996.

Numaguti, A., Origin and recycling processes of precipitating water over the Eurasian continent: Experiments using an atmospheric general circulation model, J. Geophys. Res., 104, 19571972, 1999.

Philander, S. G. H., D. Gu, D. Halpern, G. Lambert, N. -C. Lau, T. Li and R. C. Pacanowski, The role of low-level stratus clouds in keeping the ITCZ mostly north of the equator, J. Climate, 9, 2958-2972, 1996.

Rajagopalan, B., Y. Kushnir and Y. Tourre, Observed decadal midlatitude and tropical Atlantic climate variability, Geophys. Res. Lett., 25, 3967-3970, 1998.

Robertson, A. W., C. R. Mechoso and Y. -J. Kim, The influence of Atlantic sea surface temperature anomalies on the North Atlantic Oscillation, J. Climate, 13, 122-138, 2000.

Rodwell, M. J., D. P. Rowell and C. K. Folland, Oceanic forcing of the wintertime North Atlantic Oscillation and European climate, Nature, 398, 320-323, 1999.

Servain, J., Simple climate indices for the tropical Atlantic Ocean and some applications, J. Geophys. Res., 96, 15137-15146, 1991.

Sutton, R.T., S.P. Jewson and D.P. Rowell, The elements of climate variability in the tropical Atlantic region, J. Climate, 13, 3261-3284, 2000.

Watanabe, M. and M. Kimoto, Tropical-extratropical connection in the Atlantic atmosphere-ocean variability, Geophys. Res. Lett., 26, 2247-2250, 1999.

Xie, S.-P. and K. Saito, Formation and variability of a northerly ITCZ in a hybrid coupled AGCM: Continental forcing and ocean-atmospheric feedback, J. Climate, 14, in press, 2001.

Xie, S.-P. and Y. Tanimoto, A pan-Atlantic decadal climate oscillation, Geophys. Res. Lett., 25, 2185-2188, 1998.

Y. Okumura and S.-P. Xie, Department of Meteorology, University of Hawaii at Manoa, 2525 Correa Road, Honolulu, HI 96822. (e-mail: yuko@soest.hawaii.edu; xie@soest.hawaii.edu)

A. Numaguti and Y. Tanimoto, Graduate School of Environmental Earth Science, Hokkaido University, Sapporo 060-0810, Japan.

(e-mail:numa@ees.hokudai.ac.jp; tanimoto@ees.hokudai.ac.jp)

(Received October 30, 2000; revised January 25, 2001; accepted February 2, 2001.) 